\title{
Management effectiveness evaluation of world cultural landscape heritage: a case from China
}

\author{
Jiami Zhou', Wenhui Wang ${ }^{1 *}$, Jianqin Zhou', Zhuting Zhang ${ }^{1}$, Zixian Lu' and Zhiqiang Gong ${ }^{1,2}$
}

\begin{abstract}
World cultural landscape heritage (WCLH), recognized as a combination of cultural relics and natural landscapes with outstanding significance and universal value, is unique in terms of its differentiation from the deliberate human creativity of general cultural heritage and the "deartificialization" of natural heritage. To date, the management of WCLH has become increasingly standardized. However, with the prevalence of heritage resource development activities such as heritage tourism, the phenomenon of "urbanization", "commercialization", "artificialization" and other issues have gradually emerged in WCLH sites. Thus, the management issues of WCLH have become increasingly serious, leading to intense concerns about the unsustainable development of WCLH. Drawing inspirations from management effectiveness (ME) evaluation research of protected areas and acknowledging the uniqueness of WCLH, this study constructs a WCLH ME evaluation system consisting of four general criteria (management foundation, management system, management measures and management performance), 16 factors and 34 indicators. The evaluation system is applied and verified through an empirical study of five existing WCLH sites in China. The empirical results show that the ME of Chinese WCLH is at a "good" level. Specifically, the management of Chinese WCLH is overall impressive in indicators of management planning, heritage protection performance and economic performance but shows deficiency in indicators of protection fees, management infrastructure, management assessment, management institution, social performance, etc. Finally, this study discusses the management issues of respective heritage sites to provide suggestions and inspirations for the development, protection and management of the sites and other cultural landscapes in China and even the world.
\end{abstract}

Keywords: World cultural landscape heritage, Management effectiveness, Evaluation, Indicator system, China

\section{Introduction}

As a special category of World Heritage, World Cultural Landscape Heritage (WCLH) is the combined work of a particular geographical environment and human beings [1] that is recognized as irreplaceable and rare by the United Nations Educational, Scientific and Cultural Organization and the World Heritage Committee. Generally, after being added to the World Heritage

\footnotetext{
*Correspondence: whwang@ncu.edu.cn

1 School of Tourism, Nanchang University, Nanchang 330031, Jiangxi, China

Full list of author information is available at the end of the article
}

List, the development focus of cultural landscapes turns from application to follow-up management, which has brought more serious challenges for heritage management departments in terms of management ability, management measures, management resources, etc. Usually, it is believed that the heritage designation will lead to higher professionalization of management bodies and considerable improvement of their awareness of heritage protection; consequently, the management of WCLH will become increasingly satisfactory, and the authenticity and integrity of the heritage site will be protected. However, there are a number of cases reported at individual WCLH sites in which respective cultural landscapes

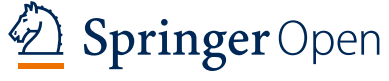

(c) The Author(s) 2022. Open Access This article is licensed under a Creative Commons Attribution 4.0 International License, which permits use, sharing, adaptation, distribution and reproduction in any medium or format, as long as you give appropriate credit to the original author(s) and the source, provide a link to the Creative Commons licence, and indicate if changes were made. The images or other third party material in this article are included in the article's Creative Commons licence, unless indicated otherwise in a credit line to the material. If material is not included in the article's Creative Commons licence and your intended use is not permitted by statutory regulation or exceeds the permitted use, you will need to obtain permission directly from the copyright holder. To view a copy of this licence, visit http://creativecommons.org/licenses/by/4.0/. The Creative Commons Public Domain Dedication waiver (http://creativeco mmons.org/publicdomain/zero/1.0/) applies to the data made available in this article, unless otherwise stated in a credit line to the data. 
have been seriously damaged, and serious issues such as "urbanization", "commercialization", "artificialization" and "heritage islands" have emerged. Unless effective management has been carried out at WCLH sites, the intrinsic contradiction between the development and the protection of heritage resources could seriously damage economic, social and ecological aspects of the sustainable development of the sites. With this background, it is of considerable importance and necessity to enhance the management effectiveness (ME) of WCLH [2,3].

"Effective Management" was originally proposed by Drucker [4] as a notion contrary to inefficient or ineffective corporate management [4]. It contains five essential elements: objectives, decision-making, implementation, supervision, and managers. Since then, issues surrounding effective management have received increasing attention from scholars and have gradually been applied to the fields of human resources management, quality control, teaching management, sustainable development of natural and cultural resources, etc., [5-7]. In the field of heritage management, the World Commission on Protected Areas of the International Union for Conservation of Nature first proposed the Protected Areas Management Effectiveness (PAME) evaluation framework, which lists context, planning, inputs, process, outputs and outcomes as key elements of "the assessment of how well protected areas are being managed" [8]. Since the framework can effectively evaluate "the extent to which management is protecting values and achieving goals and objectives", it is widely applied in the practice and research of protected areas management [8]. Based on the PAME framework, a number of tools have been developed by individuals and organizations to further evaluate the ME of protected areas, such as rapid assessment and prioritization of protected area management $[2,9,10]$ and management effectiveness tracking tools [11, 12]. To date, ME evaluation has been acknowledged as a scientific way to systematically evaluate resource management status and commonly appears in the studies of nature reserves [13], wetland parks [14], forest parks [15] and other types of protected areas [16-18]. Under such rich research efforts, the technology of ME evaluation in protected areas has become increasingly mature [2], and the respective tools have also been empirically applied, verified and supported internationally [19]. In the field of cultural landscapes, effective management is crucial for the sustainable development of heritage sites [20, 21], while a scientific and comprehensive ME evaluation system of WCLH is the key to achieving such sustainable development. Unfortunately, to the best of our knowledge, there are few theoretical and empirical ME evaluation studies on cultural landscapes, except Xu [22] and Xu et al. [23]. In those works, the selection of indicators to conduct
ME evaluation in the context of cultural landscapes was initially discussed; however, it is regretable that the proposed evaluation system was not empirically applied and supported. Considering that ME evaluation research has become normative in terms of indicator systems and evaluation methods in the field of protected areas [19] and that there exists high similarity in the goals of establishment and the elements of management between protected area cultural landscape heritage, the management practice and research of WCLH could probably draw inspiration from the ME evaluation of protected areas [3].

Under the above empirical and theoretical background, this research attempts to construct a WCLH ME evaluation system and examines its scientificity and applicability through a case study of WCLH sites in China. The purpose of the research is two-fold: (1) to offer a framework for ME evaluation research of cultural landscape heritage with reference to ME evaluation research of protected areas and (2) to provide useful guidelines for the effective management of cultural landscape heritage in China and the world.

\section{Construction of WCLH ME evaluation system \\ Selection of evaluation indicators}

Four specific steps were carried out in this study to construct the WCLH ME evaluation system. First, an indicator database with 1686 appropriate evaluation indicators was built by extracting indicators from existing ME systems or frameworks. The systems and frameworks were researched thoroughly within two kinds of sources. The first is the documents issued by institutions and organizations relevant to the management of protected areas and cultural heritage, such as the WCPA evaluation framework, Convention Concerning the Protection of the World Cultural and Natural Heritage, and Operational Guidelines for the Implementation of the World Heritage Convention. Concerning the particularity of the Chinese context in this study, documents issued by Chinese governments and institutions were given special attention, for example, Standard for the Assessment of Nature Reserve Management (HJ 913-2017), Assessment Standard of National Wetland Parks, Technical Specifications for the Management of Protected Marine Areas (GB/ T19571-2004), etc. The other source is academic papers indexed in the China National Knowledge Infrastructure, which is the world's largest database of Chinese knowledge resources. For the latter, 196 articles that addressed ME evaluation of protected areas were identified and referenced. Second, with the assistance of NVivo 12 software, the indicators generated in the previous step were screened, refined, and integrated according to their correlation and logical relationship with each other. Through 
a process of induction and deduction analysis, a draft of the general ME evaluation system was constructed. Third, the evaluation system generated in the last step was revised according to the uniqueness of WCLH. Fourth, consultation with experts in the field of cultural heritage management on the built evaluation system was carried out to improve the scientificity and applicability of the system. Based on the feedback from the experts consulted, the system was further revised such that an evaluation system comprising four general criteria at the first layer, 16 factors at the second layer, and thirty-four indicators at the third layer was built (Fig. 1).

Therefore, based on the elements of effective management identified by Drucker [4], referring to the findings of ME evaluation research of protected areas and acknowledging the uniqueness of cultural landscapes, this study constructs an ME evaluation system applicable to WCLH. Through a process of screening

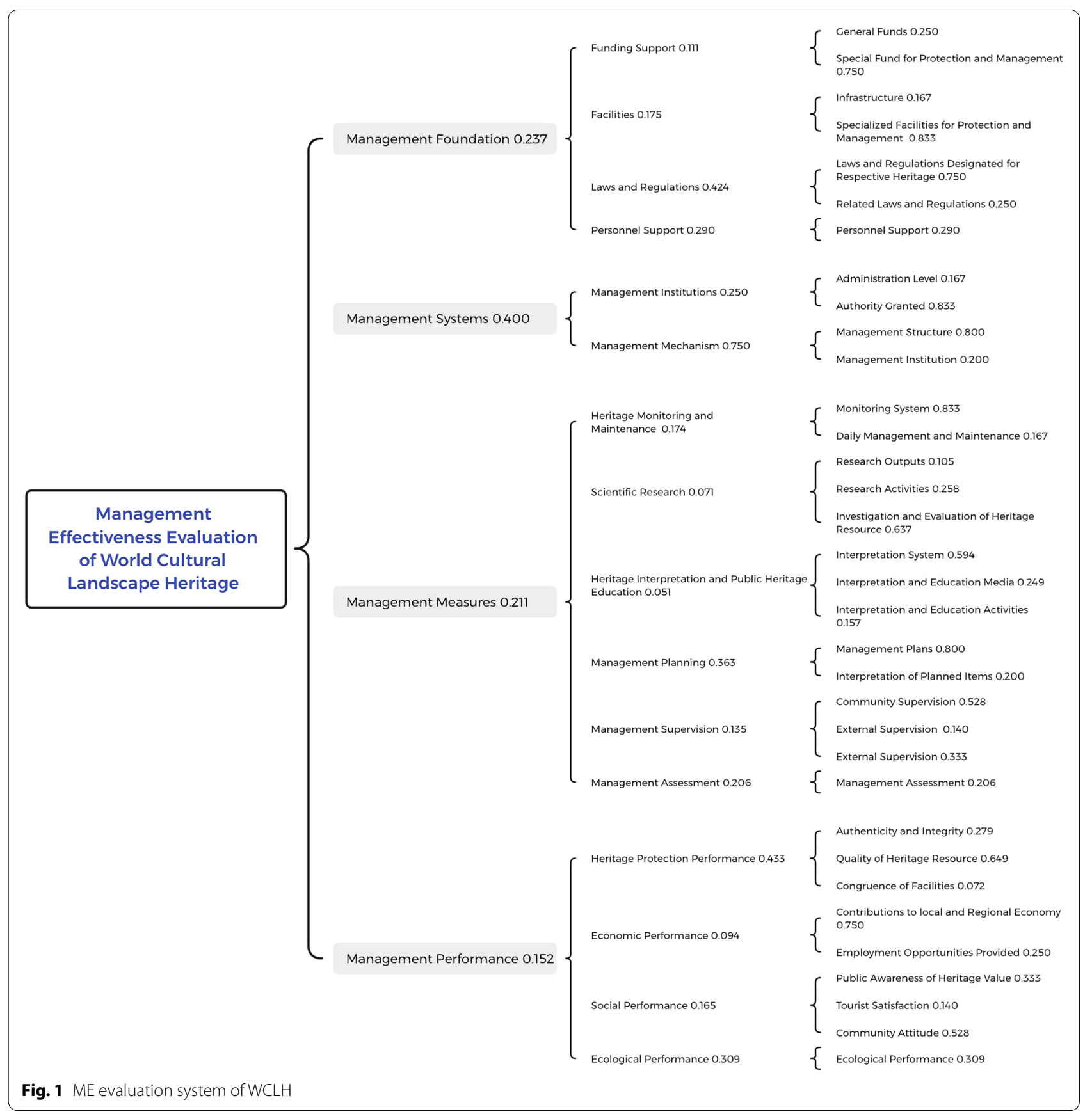


relevant literature and extracting, refining and integrating indicators from the literature, this study proposes an ME evaluation system of WCLH that includes the following four general criteria: management foundation, management system, management measures and management performance. First, as the basis for the management of WCLH, the management foundation provides necessary support in terms of funding [3], facilities [3], laws and regulations [24], personnel [14], etc. Second, a reasonable management system, which consists of management institutions and management mechanisms [25], could simplify the management process and improve management efficiency [26], therefore contributing to the sustainable development of WCLH. Third, carrying out management measures and activities is a necessary and critical means to achieve the effective management of WCLH, manifested in the effects of heritage monitoring and maintenance [26, 27] heritage interpretation and public heritage education [26], scientific research [26], management planning [14], management supervision [14], and management assessment [12] throughout the management process. Finally, management performance, which could be examined in heritage protection [28], economic [29], social [8,30] and environmental $[31,32]$ dimensions, directly reflects the level of management effectiveness of WCLH [26].

\section{Weight assignment of indicators}

In the process of constructing an evaluation system for the ME of WCLH, this study comprehensively uses the analytic hierarchy process (AHP) method and the Delphi method. The AHP is a simple, practical method that has the advantages of hierarchizing complex issues and quantifying qualitative questions as well as systematically determining the specific weight value of factors at each layer according to their importance. However, the employment of the Delphi method could avoid the issue of subjectivity and increase the rationality of the weight-giving of indicators. Based on the preconstructed indicator system, a questionnaire about ME evaluation of WCLH was designed and sent to a variety of experts for consultation. The experts, who are all professionals in the field of heritage management and protection, were randomly invited. Finally, thirty-six completed questionnaires were returned from the experts. MATLAB was then utilized to analyze the questionnaire results and to calculate the weight of each indicator. The outcome of weight assignment of indicators that have passed the consistency test is shown in Fig. 1.

\section{Case study}

\section{Study areas}

Through November 2021, there were five WCLHs in China: Lushan National Park (Lushan) (1996, Jiangxi Province), Mount Wutai (2009, Shanxi Province), West Lake Cultural Landscape of Hangzhou (West Lake) (2011, Zhejiang Province), Cultural Landscape of Honghe Hani Rice Terraces (Hani Rice Terraces) (2013, Yunnan Province), and Zuojiang Huashan Rock Art Cultural Landscape (Huashan Rock Art) (2016, Guangxi Province). Lushan, a scene that is a perfect blend of of river, hills and lake and historic buildings and features such as Taoist and Buddhist temples and landmarks of Confucianism, has inspired countless artists who developed an aesthetic approach to nature found in Chinese culture. Mount Wutai, with its five flat peaks, is a sacred Buddhist mountain that catalogs the way in which Buddhist architecture developed and influenced palace building in China for over a millennium. West Lake, comprising numerous temples, pagodas, pavilions, gardens and ornamental trees as well as causeways and artificial islands, has influenced garden design in the rest of China as well as Japan and Korea over the centuries and makes an exceptional testimony to the cultural tradition of improving landscapes to create a series of vistas reflecting an idealized fusion between humans and nature. The Hani Rice Terraces, an integrated farming system developed over the past 1300 years, demonstrates extraordinary harmony between the Hani people and their environment, both visually and ecologically, based on its exceptional and long-standing social and religious structures. Huashan Rock Art, located on the steep cliffs in the border regions of southwest China, comprises 38 sites of rock art that illustrate the life and rituals of the Luoyue people. Each of these WCLHs is unique in terms of representing the natural environment, socioeconomic development, and cultural evolution of the associated regions. The ME of these WCLHs may also vary in relation to their differences in heritage features, management bodies, history of world heritage listing, as well as modes and levels of development activities, in particular heritage tourism. Therefore, this study conducts a comparative analysis of the ME of the five Chinese WCLHs with the constructed evaluation system with the aims of making a rigorous examination of the applicability of the evaluation system and offering an overall investigation into the status quo of the management of WCLHs in China. The paper will apply the constructed evaluation system to five WCLH sites and comprehensively compare the adaptability of the development status and the evaluation results, which can further verify the operability. 


\section{Data collection and analysis}

To conduct a systematic and comprehensive examination of the ME of the case WCLHs, a variety of data sources were collected and utilized in this study. First, field studies of the WCLH sites were undertaken between August 2020 and October 2021. On-site observations that focused on the facilities, management measures and management performance of individual heritage sites were carried out, and interviews surrounding key items of the evaluation system were conducted with local residents, government officials, and tourists. Second, second-hand resources, another major data source for this study, were used to offer a more nuanced understanding of the ME of the WCLHs. On the one hand, journal articles, theses, newspapers, reports, books and other materials that are relevant to the management and protection of respective heritage sites were collected through the China National Knowledge Infrastructure, the aforementioned largest database of Chinese knowledge resources in the world together with its search engines. On the other hand, government reports, management policies, planning documents and other materials related to heritage management and protection were collected through the official websites of individual WCLHs and their administrative departments. Finally, online tourist reviews of respective WCLH sites on Ctrip and Tuniu, two major online service platforms in China, were collected and analyzed to offer supplementary views on the management status of the case WCLHs. Word frequency analysis, semantic network analysis, and sentiment analysis of the reviews were performed using ROST software.

Afterward, six researchers who are associated with this research project independently scored individual evaluation indicators of each case WCLH based on the data generated in the previous stage. A 5-point Likert scale is used for scoring, and 1-5 points are assigned according to the ME of case WCLHs from low to high. According to the scores the WCLHs achieved, their overall ME and performance in regard to different criteria, factors and indicators are classified into four grades: outstanding (not less than 4 and not larger than 5 points), good (not less than 3 and less than 4), barely satisfactory (not less than 2 and less than 3), deficient (not less than 1 and less than 2) and poor (less than 1). The overall score of the ME of each individual WCLH site was calculated according to Equation 1, where $M$ represents the overall score, i signifies individual evaluation indicators, Ai signifies the weight of indicator $i$, and $\mathrm{Wi}$ denotes the average score that the six researchers assigned to each indicator.

$$
\mathrm{M}=\sum_{i=1}^{34} A \mathrm{i} * W \mathrm{i}
$$

\section{Results}

The ME evaluation of the five WCLHs in China based on the evaluation system constructed shows that the overall ME scores of Lushan, West Lake, Mount Wutai, Hani Rice Terraces, and Huashan Rock Art are 3.75, 4.13, 3.48, 3.48 and 3.11, respectively, with an average score of 3.59 (Table 1). Among them, the ME grade of West Lake is outstanding, and the ME grades of the other WCLHs are good, indicating that the management of these WCLHs still has much room to improve. The evaluation result is in line with the overall management status of the five WCLHs in China reported by interviewees, in the second collection of data, and in the online tourist reviews, indicating that the ME evaluation system of WCLHs constructed is practically operable and relatively scientific.

With regard to the ME evaluation result at the general criteria layer, the average scores of the five Chinese WCLHs in terms of management foundation, management system, management measures and management performance are $3.69,3.45,3.74$ and 3.58 , respectively. This indicates that the management of WCLHs in China is at a good level overall in the aspects of "management foundation", "management system", "management measures" and "management performance" but still has large room for improvement, especially in the area of "management system", consistent with the development and management of world heritage in China in recent decades. First, a world heritage listing has often been considered an effective way to boost regional development in the context of China. Whether they are in the process of applying for listing or subsequent development initiatives, the local government of associated heritage sites, especially those at the prefecture and county levels, usually invests a great deal of personnel, material and financial resources to lay a good foundation for further development activities such as heritage tourism. Second, except for the Hani Rice Terraces, the other WCLH sites have long been listed as national protected areas and developed as tourist attractions before launching their listing application initiatives. Therefore, rich legacies in terms of personnel, facilities, regulations, and experiences in heritage monitoring and maintenance, heritage interpretation and public heritage education, scientific research, and so forth were left for associated WCLH sites. Third, after successfully being listed as a World Heritage site, their relative heritage significance soon became renowned. Meanwhile, the strong development initiatives made by local government and respective agents, for example heritage tourism, may generate considerable economic benefits. For such reasons, the management performance of WCLHs is more often than not maintained at a satisfactory level. Last, institutional and administrative issues, especially those caused by multiple 
Table 1 Score table for ME evaluation of WCLH in China

\begin{tabular}{|c|c|c|c|c|c|c|}
\hline \multirow[t]{2}{*}{ Criteria (A), factors (B), indicators (C) } & \multicolumn{6}{|c|}{ Actual score } \\
\hline & Lushan & West Lake & Mount Wutai & $\begin{array}{l}\text { Hani Rice } \\
\text { Terraces }\end{array}$ & $\begin{array}{l}\text { Huashan } \\
\text { Rock Art }\end{array}$ & Overall average \\
\hline Management foundation A1 & 3.69 & 4.25 & 3.73 & 3.54 & 3.25 & 3.69 \\
\hline Funding support B1 & 4.13 & 4.31 & 3.74 & 3.60 & 3.23 & 3.80 \\
\hline General funds C1 & 4.23 & 4.35 & 3.93 & 3.90 & 3.75 & 4.03 \\
\hline Special funds for protection and management C2 & 4.10 & 4.30 & 3.68 & 3.50 & 3.05 & 3.73 \\
\hline Facilities B2 & 3.66 & 4.13 & 3.39 & 2.88 & 3.04 & 3.42 \\
\hline Infrastructure C3 & 4.05 & 4.30 & 3.45 & 3.13 & 2.73 & 3.53 \\
\hline Particular facilities for protection and management C4 & 3.58 & 4.10 & 3.38 & 2.83 & 3.10 & 3.40 \\
\hline Laws and regulations B3 & 3.86 & 4.37 & 3.98 & 4.06 & 3.49 & 3.95 \\
\hline Laws and regulations designated for respective heritage $C 5$ & 3.88 & 4.33 & 3.98 & 4.13 & 3.48 & 3.96 \\
\hline Related laws and regulations C6 & 3.83 & 4.50 & 3.98 & 3.83 & 3.53 & 3.93 \\
\hline Personnel support B4 & 3.28 & 4.13 & 3.58 & 3.17 & 3.05 & 3.44 \\
\hline Personnel support C7 & 3.28 & 4.13 & 3.58 & 3.17 & 3.05 & 3.44 \\
\hline Management system A2 & 3.77 & 4.03 & 3.39 & 3.20 & 2.86 & 3.45 \\
\hline Management institutions B5 & 3.58 & 3.69 & 2.80 & 2.56 & 2.65 & 3.06 \\
\hline Administrative level C8 & 3.63 & 3.63 & 3.18 & 3.03 & 2.78 & 3.25 \\
\hline Authority granted C9 & 3.58 & 3.70 & 2.73 & 2.47 & 2.63 & 3.02 \\
\hline Management mechanism B6 & 3.84 & 4.15 & 3.59 & 3.41 & 2.93 & 3.58 \\
\hline Management structure C10 & 3.95 & 4.30 & 3.73 & 3.50 & 2.93 & 3.68 \\
\hline Management institution C11 & 3.38 & 3.55 & 3.05 & 3.03 & 2.95 & 3.19 \\
\hline Management measures A3 & 3.90 & 4.25 & 3.44 & 3.84 & 3.29 & 3.74 \\
\hline Heritage monitoring and maintenance B7 & 4.10 & 4.40 & 4.06 & 3.94 & 3.67 & 4.03 \\
\hline Monitoring system C12 & 4.15 & 4.43 & 4.15 & 4.03 & 3.75 & 4.10 \\
\hline Daily management and maintenance $\mathrm{C} 13$ & 3.83 & 4.28 & 3.60 & 3.50 & 3.30 & 3.70 \\
\hline Scientific research B8 & 3.46 & 3.79 & 3.23 & 3.43 & 3.25 & 3.43 \\
\hline Research outputs C14 & 4.03 & 4.45 & 3.18 & 3.10 & 3.68 & 3.69 \\
\hline Research activities C15 & 3.60 & 4.10 & 3.25 & 2.97 & 3.13 & 3.41 \\
\hline Investigation and evaluation of heritage resources $\mathrm{C} 16$ & 3.33 & 3.55 & 3.23 & 3.67 & 3.23 & 3.40 \\
\hline Heritage interpretation and public heritage education B9 & 3.80 & 4.22 & 3.64 & 3.97 & 3.52 & 3.83 \\
\hline Interpretation system C17 & 3.75 & 4.13 & 3.60 & 3.97 & 3.33 & 3.76 \\
\hline Interpretation and education media C18 & 3.65 & 4.38 & 3.35 & 3.73 & 3.48 & 3.72 \\
\hline Interpretation and education activities $\mathrm{C} 19$ & 4.20 & 4.33 & 4.23 & 4.33 & 4.30 & 4.28 \\
\hline Management planning B10 & 4.32 & 4.42 & 3.92 & 3.93 & 4.00 & 4.12 \\
\hline Management plans C20 & 4.33 & 4.43 & 3.88 & 3.97 & 4.15 & 4.15 \\
\hline Implementation of planned items C21 & 4.28 & 4.38 & 4.10 & 3.80 & 3.38 & 3.99 \\
\hline Management supervision B11 & 3.26 & 3.99 & 2.98 & 3.38 & 2.26 & 3.17 \\
\hline Community supervision C22 & 3.20 & 3.93 & 2.95 & 3.33 & 2.08 & 3.10 \\
\hline External supervision C23 & 3.58 & 3.78 & 3.23 & 3.10 & 2.50 & 3.24 \\
\hline Internal supervision C24 & 3.23 & 4.18 & 2.93 & 3.57 & 2.45 & 3.27 \\
\hline Management assessment B12 & 3.60 & 4.15 & 2.38 & 4.00 & 2.25 & 3.28 \\
\hline Management assessment C25 & 3.60 & 4.15 & 2.38 & 4.00 & 2.25 & 3.28 \\
\hline Management performance A4 & 3.58 & 4.04 & 3.35 & 3.60 & 3.34 & 3.58 \\
\hline Heritage protection performance B13 & 3.34 & 3.92 & 3.24 & 3.51 & 3.33 & 3.47 \\
\hline Authenticity and integrity C26 & 3.30 & 3.98 & 3.33 & 3.73 & 3.40 & 3.55 \\
\hline Quality of heritage resources C27 & 3.38 & 3.90 & 3.18 & 3.37 & 3.33 & 3.43 \\
\hline Congruence of facilities C28 & 3.13 & 3.90 & 3.48 & 3.90 & 3.08 & 3.50 \\
\hline Economic performance B14 & 4.24 & 4.41 & 3.99 & 3.62 & 3.23 & 3.90 \\
\hline Contributions to local and regional economy C29 & 4.30 & 4.45 & 4.00 & 3.63 & 3.20 & 3.92 \\
\hline
\end{tabular}


Table 1 (continued)

\begin{tabular}{|c|c|c|c|c|c|c|}
\hline \multirow[t]{2}{*}{ Criteria (A), factors (B), indicators (C) } & \multicolumn{6}{|c|}{ Actual score } \\
\hline & Lushan & West Lake & Mount Wutai & $\begin{array}{l}\text { Hani Rice } \\
\text { Terraces }\end{array}$ & $\begin{array}{l}\text { Huashan } \\
\text { Rock Art }\end{array}$ & Overall average \\
\hline Employment opportunities provided C30 & 4.05 & 4.30 & 3.95 & 3.60 & 3.30 & 3.84 \\
\hline Social performance B15 & 3.72 & 4.07 & 3.57 & 3.69 & 3.22 & 3.65 \\
\hline Public awareness of heritage value C31 & 4.03 & 4.33 & 3.78 & 3.70 & 3.45 & 3.86 \\
\hline Tourist satisfaction C32 & 3.60 & 4.33 & 3.48 & 3.63 & 3.28 & 3.66 \\
\hline Community attitude $\mathrm{C} 33$ & 3.55 & 3.83 & 3.45 & 3.70 & 3.05 & 3.52 \\
\hline Ecological performance B16 & 3.65 & 4.08 & 3.20 & 3.67 & 3.45 & 3.61 \\
\hline Ecological performance C34 & 3.65 & 4.08 & 3.20 & 3.67 & 3.45 & 3.61 \\
\hline Overall weighted score & 3.75 & 4.13 & 3.48 & 3.48 & 3.11 & 3.59 \\
\hline Level & Good & Excellent & Good & Good & Good & Good \\
\hline
\end{tabular}

management bodies as well as their overlapping functions and conflicting interests, have been reported in a number of cases of world heritage sites in China, including the case studies of this study. China has recently endeavored to carry out management institution reform. However, the substantial change in the management system and optimal solution of related matters may still require more time and effort. It is worth noting that the ME evaluation result of West Lake is outstanding in all general criteria, that other WCLHs are evaluated as good in most criteria and that Huashan Rock Art is rated as barely satisfactory in the criterion of "management system". That evaluation result could offer implications for the management departments of individual WCLHs to carry out criterion-targeted strategies to improve the ME of respective heritage sites.

Regarding the ME evaluation result at the factor level, overall, the ME of WCLHs in China is rated as outstanding only in the factors of "heritage monitoring and maintenance" and "management planning" and as good in all other factors. To better protect its cultural landscape heritage, China has made great investments in providing personnel, funding or regulatory support. At most heritage sites, an all-round monitoring system that is connected to provincial and national monitoring platforms is built to offer $24 \mathrm{~h}$ monitoring of not only the landscapes and the environment they are embedded in but also the activities of actors such as tourists. In addition, particular departments that are responsible for carrying out daily management and maintenance duties are established in the majority of heritage sites. Regarding the specific situation of case WCLHs, West Lake stands out for receiving 11 outstanding grades out of 16 factors. Being evaluated as outstanding in 3 factors, Lushan is relatively moderate. The situations for Mount Wutai, Hani Rice Terraces, and Huashan Rock Art are to some extent worrying, as they only receive 1 outstanding grade and are scored barely satisfactory in 2, 1 , and 4 factors, respectively. Overall, the evaluation result of the "management institutions" factor (3.06) is far from outstanding, with Mount Wutai, Hani Rice Terraces, and Huashan Rock Art all getting barely satisfactory scores for this factor. The situation may be directly related to the institutional and administrative issues discussed in the previous section. Regarding the factor of "management assessment", West Lake and Hani Rice Terraces receive outstanding grades, while Mount Wutai and Huashan Rock Art are rated as barely satisfactory, indicating that the latter should learn from the valid experience of the former. West Lake made the very first attempt in China to conduct an expert review on the implementation of its development and management plans. The local government of the Hani Rice Terraces initiated a self-assessment of the management of the heritage site and issued the assessment report to the public for supervision. The result that Huashan Rock Art is rated as barely satisfactory in the factor of "management supervision" is also noteworthy.

Considering the ME evaluation results at the indicator layer, the ME of WCLHs in China overall is evaluated as outstanding in indicators of "general funds", "monitoring system", "interpretation and education activities", and "management plans", and good in all other indicators. With respect to the specific results of the case WCLHs, Lushan, West Lake, Mount Wutai, Hani Rice Terraces, and Huashan Rock Art are rated as outstanding in 10, $24,4,4$, and 2 out of 34 indicators and as barely satisfactory in $0,0,3,2$, and 9 indicators, respectively. To be more nuanced, Huashan Rock Art is barely satisfactory in all indicators under the factors of "management institutions", "management mechanisms", "management supervision", and "management assessment" as well as in the indicator of "infrastructure". According to field 
observations, the development activities surrounding Huashan Rock Art remain very rudimentary. For example, tourism products offered at this heritage site have been limited to a sightseeing boat tour of the rock art and a live themed performance at the rock art. In addition, with a meager score of 3.05 , its evaluation result in the indicators of "personnel support" and "community attitude" is also worrisome. For this case, a serious campaign seems necessary to better develop, protect and manage the cultural landscape of Huashan Rock Art. Another issue that needs more attention is that the management bodies of Mount Wutai, Hani Rice Terraces, and Huashan Rock Art have been granted limited authority, revealed in their barely satisfactory evaluation result in the indicator of "authority granted". These indicator-based evaluation results point out concrete and detailed directions for the WCHLs in China to advance their ME in future management practices.

\section{Conclusion and discussion}

This study makes a preliminary attempt in terms of developing an ME evaluation system applicable to the context of WCLH. With reference to the ME evaluation of protected areas and acknowledging the uniqueness of WCLH, an evaluation system that comprises four general criteria (management foundation, management system, management measures and management performance), 16 factors, and 34 indicators is constructed. The scientificity and operationality of the system is verified through an examination of WCLHs in China, namely, Lushan, West Lake, Mount Wutai, Hani Rice Terraces, and Huashan Rock Art. The ME evaluation results of the case WCLHs are West Lake (4.13 points, outstanding), Lushan (3.75 points, good), Hani Rice Terraces (3.48 points, good), Mount Wutai (3.48 points, good), and Huashan Rock Art (3.11 points, good). These results show that the management of WCLHs in China is overall effective but has considerable room for optimization.

The findings also demonstrate that overall, the management of WCLHs in China performs well in indicators of "general funds", "monitoring system", "interpretation and education activities", and "management plans", as well as factors of "heritage monitoring and maintenance" and "management planning." It is rated as good in other indicators and factors as well as all criteria of management foundation, management system, management measures and management performance. The scores that Lushan, West Lake, Mount Wutai, Hani Rice Terraces, and Huashan Rock Art achieved in each particular criteria, factor, and indicator may vary considerably to the extent that they are assigned to different grades. Out of 34 indicators,
Lushan, West Lake, Mount Wutai, Hani Rice Terraces, and Huashan Rock Art are rated as outstanding in 10, $24,4,4$, and 2 indicators and as barely satisfactory in 0 , $0,3,2$, and 9 indicators, respectively. Overall, the management of WCLHs in China has made considerable achievements on the one hand and has much room for improvement on the other hand, particularly in terms of laying more solid management foundations, building more efficient management systems, and carrying out more systematic management measures.

The constructed ME evaluation system is significant in terms of providing a scientific and useful tool that can be adopted in the ME evaluation of cultural landscape heritage sites in different contexts. To the best of our knowledge, this is the first empirical attempt in the area. The system could offer rich implications for the development, protection and management of cultural landscape heritage in terms of carrying out our practices that could lead to high ME. The case study of the WCLHs in China in this study is also meaningful regarding presenting an overall picture of the management status quo of WCLHs in China, revealing the serious management issues existing in each WCLH site and offering inspirations for the management practices of respective WCLH sites. Although a variety of data collection methods have been employed to gather rich research sources, there are still some data that are not readily accessible or not yet available to the public, which may to a slight extent affect the evaluation results of the WCLHs in China. In addition, the management vision and practices of cultural landscape heritage may vary in different geographical contexts. Considering these limitations, more theoretical and empirical studies of the ME evaluation of cultural landscape heritage are called for to advance our knowledge in the field.

\section{Abbreviations \\ WCLH: World cultural landscape heritage; ME: Management effectiveness; AHP: Analytic hierarchy process. \\ Acknowledgements \\ The authors would like to show their gratitude to Miss Lisha Xia and Miss Menghan Zhou for their assistance in data collection and analysis.}

\section{Authors' contributions}

Conceptualization: WW; methodology: WW; data collection and analysis: JZ, WW, ZZ, ZL and ZG; writing-original draft: JZ, ZZ, ZL; writing-review and editing: WW, JZ, and ZG; supervision: WW, ZG; funding acquisition: ZG. All authors read and approved the final manuscript.

\section{Funding}

The research is supported by the National Social Science Fund of China (17BGL115).

Availability of data and materials

The datasets used and/or analyzed during the current study are available from the corresponding author on reasonable request. 


\section{Declarations}

\section{Competing interests}

The authors declare that they have no competing interests.

\section{Author details}

'School of Tourism, Nanchang University, Nanchang 330031, Jiangxi, China

${ }^{2}$ Wanli Administration Bureau, Nanchang 330004, Jiangxi, China.

Received: 20 November 2021 Accepted: 29 January 2022

Published online: 10 February 2022

\section{References}

1. Ji-xiang SHAN. From the "Cultural Landscape" to the "Cultural Landscape Heritage" (part one). Southeast Cult. 2010:02:7-18.

2. Ervin J. Protected area assessments in perspective. Bioscience. 2003:53(9):819-22.

3. Maxim C, Chasovschi CE. Cultural landscape changes in the built environment at World Heritage Sites: lessons from Bukovina, Romania. J Destin Mark Manag. 2021. https://doi.org/10.1016/j.jdmm.2021.100583.

4. Drucker PF. The effective executive. 1st ed. New York: Harper \& Row; 1967.

5. Alazaizeh MM, Hallo JC, Backman SJ, et al. Giving voice to heritage tourists: indicators of quality for a sustainable heritage experience at Petra, Jordan. J Tour Cult Chang. 2019;17(3):269-84.

6. Puritz AJ. Evaluating management effectiveness of marine protected areas in Cuba's southern archipelagos: a comparative analysis between Punta Francés and Jardines de la Reina National Parks. Coral Gables: University of Miami; 2017.

7. Jelinčić DA. Indicators for cultural and creative industries'impact assessment on cultural heritage and tourism. Sustainability. 2021. https://doi. org/10.3390/su13147732.

8. Hockings M. Evaluating effectiveness: a framework for assessing management effectiveness of protected areas. 2nd ed. Gland: International Union for Conservation of Nature and Natural Resources; 2006.

9. Hockings M, Stolton S, Dudley N. Evaluating effectiveness: a framework for assessing the management of protected areas. 1st ed. Gland: International Union for Conservation of Nature and Natural Resources; 2000

10. Erivin J. Rapid Assessment and prioritization of protected area management (RAPPAM) methodology. Switzerland:WWF; 2003.

11. Stolton S, Hockings M, Dudley N, MacKinnon K, Whitten T, Leverington F. Reporting progress in protected areas: a site-level management effectiveness tracking tool. 2nd ed. Gland: World Wide Fund for Nature; 2007

12. Nolte C, Agrawal A. Linking management effectiveness indicators to observed effects of protected areas on fire occurrence in the Amazon rainforest. Conserv Biol. 2013;27(1):155-65.

13. Reed MG, Egunyu F. Management effectiveness in UNESCO biosphere reserves: learning from Canadian periodic reviews. Environ Sci Policy. 2013:25:107-17.

14. Carbutt C. How objective are protected area management effectiveness assessments: a case study from the iSimangaliso Wetland Park. Koedoe. 2013:55(1):1-8.

15. Junior MGC, Biju BP, da Silva Neto EC, et al. Improving the management effectiveness and decision-making by stakeholders' perspectives: a case study in a protected area from the Brazilian Atlantic Forest. J Environ Manag. 2020;272:111083.

16. dos Santos BC, Malta A, Schiavetti A. Temporal assessment of the management effectiveness of reef environments: the role of marine protected areas in Brazil. Ocean Coast Manag. 2017;142:111-21.

17. Liu Y, Wang R, Guo T, et al. Evaluating efficiencies and cost-effectiveness of best management practices in improving agricultural water quality using integrated SWAT and cost evaluation tool. J Hydrol. 2019;577:123965

18. Rodríguez-Rodríguez D, Ibarra P, Martínez-Vega J, et al. Fine-tuning of a protected area effectiveness evaluation tool: Implementation on two emblematic Spanish National Parks. Environments. 2017. https://doi.org/ 10.3390/environments4040068
19. Leverington F, Hockings M, Costa KL. Management effectiveness evaluation in protected areas: a global study. Australia: World Commission on Protected Areas; 2008.

20. Joppa LN, Visconti P, Jenkins CN, et al. Achieving the convention on biological diversity's goals for plant conservation. Science. 2013;341(6150):1100-3.

21. López-Rodríguez F, Rosado D. Management effectiveness evaluation in protected areas of southern Ecuador. J Environ Manag. 2017;190:45-52.

22. $\mathrm{Xu} \mathrm{H}$. Selected studies on evaluation indicators of World Heritage Landscape Conservation Management. Beijing Plan Rev. 2018;02:134-7.

23. Xu H, Yu WD, Seok MJ, et al. A study on construction of management effectiveness evaluation system for world cultural heritage. J Korean Inst Tradit Landsc Archit. 2013;31(4):51-61.

24. Negru C, Gaibor ID, Hălălișan AF, et al. Management effectiveness assessment for Ecuador's National Parks. Diversity. 2020. https://doi.org/10. 3390/d12120487.

25. Wu H, Dan X, Shu Y, Liu S, Huang Y, Cao H. Indicator system and its application for effective management assessment of National Wetland Park. Wetl Sci. 2015;13(04):495-502.

26. Quan J, Ouyang Z, Xu W, Miao H. Comparison and applications of methodologies for management effectiveness assessment of protected areas. Biodivers Sci. 2010;18(01):90-9.

27. Xu X, Jiang B, Chen M, et al. Strengthening the effectiveness of nature reserves in representing ecosystem services: the Yangtze River Economic Belt in China. Land Use Policy. 2020;96:104717.

28. Zhang C. Indicators for world heritage governance evaluation and its application. J Cent South Univ For Technol. 2007:01:72-7.

29. Noaman N, Ouda H, Christiaens J. Indexing financial reporting information for heritage Management. Econ Manag. 2018. https://doi.org/10. 15240/tul/001/2018-2-013.

30. Adeleke BO, Ogunsusi K. Evaluation of factors enhancing effectiveness of destination management of nature based tourism, Lagos, Nigeria. Int Tour Hosp J. 2019:2(2):1-16.

31. de Almeida LT, Olímpio JLS, Pantalena AF, et al. Evaluating ten years of management effectiveness in a mangrove protected area. Ocean Coast Manag. 2016;125:29-37.

32. Guzman P, Pereira Roders AR, Colenbrander B. Impacts of common urban development factors on cultural conservation in world heritage cities: an indicators-based analysis. Sustainability. 2018. https://doi.org/10.3390/ su10030853.

\section{Publisher's Note}

Springer Nature remains neutral with regard to jurisdictional claims in published maps and institutional affiliations.

\section{Submit your manuscript to a SpringerOpen ${ }^{\circ}$ journal and benefit from:}

- Convenient online submission

- Rigorous peer review

- Open access: articles freely available online

- High visibility within the field

Retaining the copyright to your article

Submit your next manuscript at springeropen.com 